\title{
Normal P300 following extensive damage to the left medial temporal lobe
}

\author{
Michael D Rugg, Charles D Pickles, Douglas D Potter, Richard C Roberts
}

\begin{abstract}
Event-related potentials (ERPs) were recorded during auditory and visual "oddball" tasks from a patient with a severe verbal memory deficit due to a low grade infiltrating glioma which involved the full extent of the left medial temporal lobe. In both sensory modalities, the patient's oddball-evoked P300s were symmetrical and of normal amplitude. These findings are difficult to reconcile with the hypothesis that the hippocampus, or any other medial temporal structure, makes a substantial contribution to the scalp P300.
\end{abstract}

The P300, an endogenous component* of the scalp-recorded event-related potential (ERP), takes the form of a positive deflection with an amplitude of up to $30 \mu \mathrm{V}$ and a peak latency of between approximately 300 and $600 \mathrm{~ms}$. It exhibits a parietal-maximum scalp distribution, and a similar range of functional properties, when evoked by stimuli of any sensory modality (for a recent review see Verleger ${ }^{1}$ ). It is frequently used to study cognitive dysfunction in neurological disease. ${ }^{2}$

The P300 is commonly elicited with simple stimuli by use of the "oddball" task. In its simplest form, this task consists of an unpredictable sequence of two classes of stimulus. The subject must detect one class (the oddballs or targets), while ignoring the other more probable class (the non-targets). In comparison with the ERPs evoked by nontargets, target ERPs contain an enhanced P300, the amplitude of which is inversely related to target probability. ${ }^{3}$

Intracerebral recordings from the medial temporal lobe (MTL) have demonstrated the presence of a sizeable oddball-sensitive ERP wave, which appears to be locally generated..$^{47}$ This wave is roughly contemporaneous with the $\mathbf{P} 300$ recorded from the scalp, and shares many functional properties with the scalp component. ${ }^{5}$ Analysis of its intracerebral voltage distribution suggests that it is generated in the hippocampus, ${ }^{5}$ a conclusion consistent with reports that the wave is frequently abnormal when recorded from an MTL containing a sclerotic hippocampus. ${ }^{8-10}$

\footnotetext{
Footnote

*The term endogenous components refers to features of the ERP that are largely under the influence of psychological variables such as stimulus probability, attention, etc. These can be contrasted with exogenous components, which are influenced mainly by physical characteristics of the evoking stimulus, such as sensory modality or intensity.
}

It is uncertain whether volume-conduction of the P300-like ERP component generated in the hippocampus contributes significantly to the scalp P300. Currently, the most substantial body of relevant evidence arises from studies of the scalp P300 in patients who have had unilateral anterior temporal lobectomy for the relief of epilepsy. If the $\mathrm{P} 300$ reflects to any substantial extent the activity of bilateral MTL generators, damage to one such generator would be expected to result in a reduction in amplitude and a shift in the lateral distribution of this component. Such findings have not been obtained; the P300s of temporal lobectomy patients are neither grossly asymmetric nor reduced in amplitude..$^{11-14}$

Two problems exist in making the inference from these findings that MTL structures do not contribute to the scalp P300. First, lobectomy patients have unilateral skull defects. The effects that these might have on the amplitude and distribution of the scalp P300 are unknown (although, as noted by Knight ${ }^{15}$ and Stapleton et $a l_{,}{ }^{13}$ the likelihood that any effects exactly cancel those of a lobectomy seems very remote). Second, Knight ${ }^{15}$ points out that temporal lobectomy for the relief of epilepsy usually spares a substantial proportion of the posterior hippocampus, ${ }^{16}$ a region of the MTL which typically gives rise to high amplitude oddball-evoked ERP activity. ${ }^{5}$ The lobectomy data are therefore consistent with the hypothesis that it is the posterior rather than the anterior region of the MTL that makes a significant contribution to the scalp P300.

We describe a case in which non-surgical damage has occurred along the entire extent of the MTL of one hemisphere, but in whom the amplitude and lateral distribution of the parietal P300 are normal. This allows further evaluation of the role of MTL structures in the generation of the scalp P300.

\section{Method}

We describe a teacher aged 44 years. She presented as an emergency in November 1987, having had a first generalised tonic clonic seizure preceded by nausea, a sense of doom and seeing coloured lights. She was admitted to hospital and had two further generalised tonic clonic seizures within 24 hours. Physical examination was normal as were haematological and biochemical investigations. A CT scan of the brain showed a low attenuation area in the left posterior temporal region, with no mass effect and no enhance- 


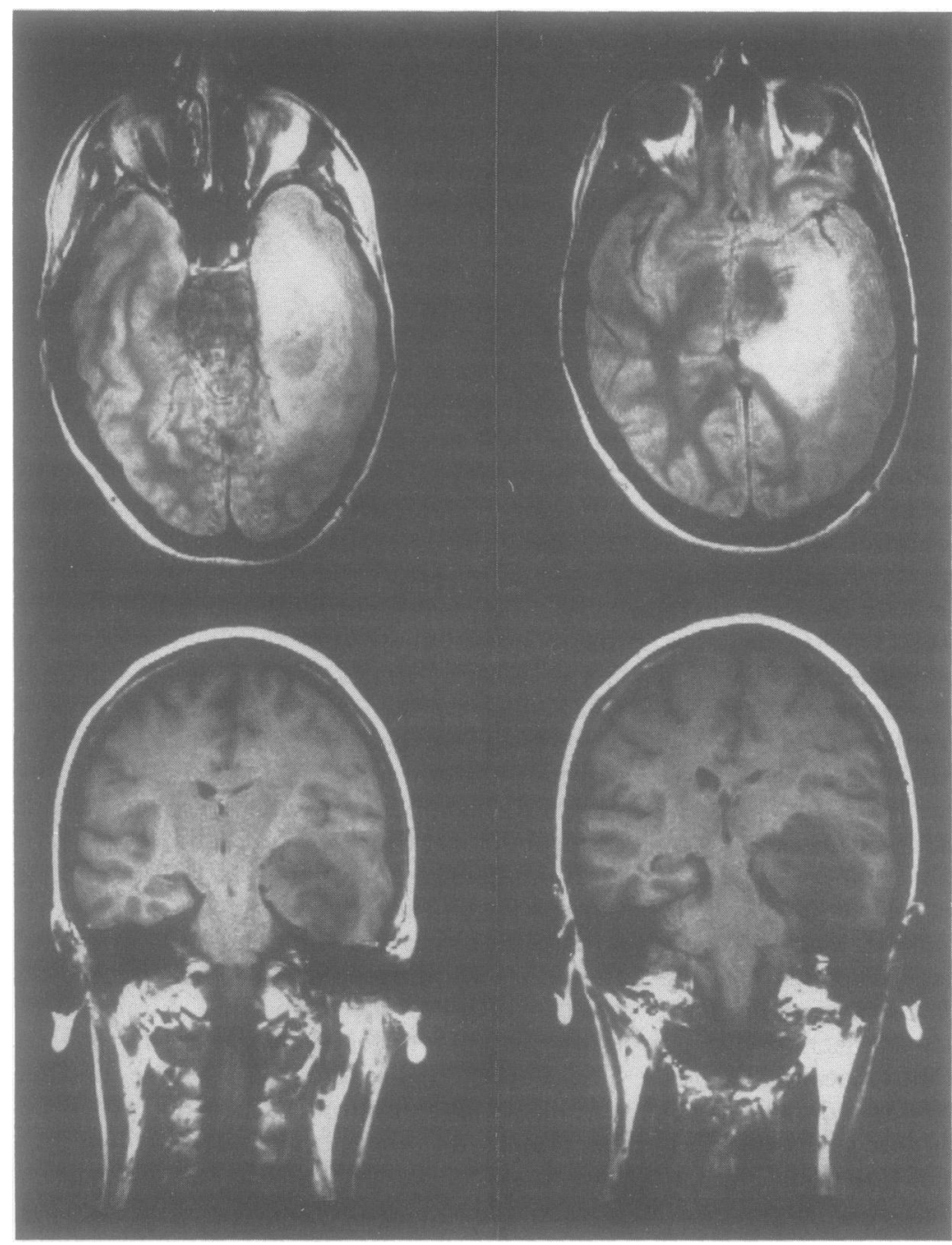

Figure 1 Horizontal and coronal MRI illustrating the extent of the pathology in the patient's left temporal lobe. biopsy showed it to be a low grade infiltrating glioma. Physical examination at this time remained normal, and there were no neurological deficits apart from her poor memory.

MRI Representative images are shown in fig 1. An abnormal signal is present throughout the left medial temporal lobe, including anterior and posterior hippocampus and parahippocampal regions. The lateral cortex appears to be spared.

Neuropsychological data Relevant details of the patient's performance on a range of tests are given in table 1. These data were obtained in January 1989. In contrast to her normal intelligence and intact immediate memory (assessed by digit span), her long-term verbal memory is considerably deficient; this is especially evident on the delayed logical memory and paired associate subtests of the Wechsler Memory Scale (Revised), and on the Rey test of auditory-verbal learning.

Control subjects The controls consisted of five individuals, one of whom was male. Three of these were healthy, and two were neurological outpatients suffering from disorders of the peripheral nervous system (cervical radiculopathy and carpal tunnel syndrome). Details of these subjects are given in table 1 .

Auditory oddball task Stimuli consisted of 80 $\mathrm{dB}$ tones $(50 \mathrm{~ms}$ duration, $10 \mathrm{~ms}$ rise and fall times, $2 \mathrm{~s}$ ISI) with a frequency of either $250 \mathrm{~Hz}$ or $500 \mathrm{~Hz}$. During an experimental run, one of these tones was designated the target, and the other the non-target. A run comprised 200 stimuli, consisting of an unpredictable sequence of targets $(p=0.25)$ and non-targets. The task was to make a rapid manual response whenever a target occurred by squeezing a thumb-switch held in the preferred hand.

Data were obtained from the patient on two runs of this task in June 1989. The controls each performed the task once. For all subjects the instructions stressed the need to respond promptly to the targets, and to minimise eyefurther seizures for three months. $A$ second CT scan, performed six weeks after the first, showed a slight decrease in the size of the low attenuation area, suggesting a cerebral infarct. Digital vascular imaging with arch and left carotid injections was normal.

Following initial admission the patient reported a marked impairment of memory for recent events, in particular for dates, times, places and names. Her memory problems have persisted since that time.

During 1988 she had infrequent episodes of left retro-orbital headache and nausea, and she had four further episodes of transient visual symptoms. The latter consisted of blurring and distortion, a bright arc flashing across the visual field or rainbows shooting from right to left. These episodes lasted between 10 and 45 minutes. The last was in October 1988 and was followed by dysphasia and a tonic clonic seizure. Her carbamazepine was then increased to $400 \mathrm{mg} /$ day and there has been no recurrence.

In October 1989 she had an MRI of the brain. This revealed that the left posterior temporal lesion was a tumour, which was now producing some mass effect. Stereotaxic
Table 1 Neuropsychological test scores of the patient and controls

\begin{tabular}{|c|c|c|}
\hline & Patient & Control mean $(S D)$ \\
\hline \multirow{4}{*}{$\begin{array}{l}\text { Age } \\
\text { WAIS-R } \\
\text { NART } \\
\text { WMS-R: Verbal } \\
\quad \text { Visual }\end{array}$} & $\begin{array}{r}45 \\
108\end{array}$ & $\begin{array}{l}44 \quad(7 \cdot 1) \\
-\end{array}$ \\
\hline & $\begin{array}{l}108 \\
107\end{array}$ & $(5 \cdot 1)$ \\
\hline & 89 & $(5.6)$ \\
\hline & 110 & $122(11 \cdot 3)$ \\
\hline PA & 6 & $22 \quad(1.8)$ \\
\hline ILM & 25 & $29 \quad(2 \cdot 2)$ \\
\hline DLM & 14 & $27 \quad(3 \cdot 1)$ \\
\hline DS & 7 & $7.0(1.4)$ \\
\hline RAVLT: I & 3 & $7,8^{2}$ \\
\hline $\begin{array}{l}\text { V } \\
\text { VI }\end{array}$ & 8 & 15,15 \\
\hline & & \\
\hline
\end{tabular}

WAIS = Wechsler Adult Intelligence Scale-Revised. NART = Estimated full-scale IQ from National Adult Reading Test.
WMS-R = Wechsler Memory Scale-Revised. Verbal = WMS-R verbal memory index. Visual = WMS-R visual WMS-R verbal memory index. Visual $=W M S-R$ visual
memory index. PA $=$ raw score of verbal paired associates memory index. PA = raw score of verbal paired associates
subtest of WMS-R. ILM = raw score of immediate recall of subtest of WMS-R. ILM = raw score of immediate recall of
logical memory sub-test of WMS-R. DLM = raw score of logical memory sub-test of WMS-R. DLM = raw score of
delayed logical memory sub-test of WMS-R. DS = maximum felayed logical memory sub-test of WMS-R. DS = maximum test. I = trial $1 ; \mathrm{V}=$ trial 5 ; VI = recall after presentation of test. I $=$ trial $1 ; \mathrm{V}=$
an interpolating list.

an interpolating list. a- Only two controls performed the RAVLT. Both subjects'
scores are shown. Lezak ${ }^{23}$ reports a mean performance for a group of 30 "professionals" on trial I as $8.6(\mathrm{SD}=1.5)$, and on trial $\mathrm{V}$ as $14.0(\mathrm{SD}=1.0)$. 
and body-movements. A short rest was given half-way through each run.

Visual oddball task This task involved the presentation of two letter strings, $\mathrm{OOO}$ and XXX. Os occurred on $75 \%$ of trials, and were designated non-targets. Xs occurred on a random $25 \%$ of trials, and, as in the auditory task, required a prompt response using a thumb-switch held in the preferred hand. The letter-strings were displayed at a moderate contrast on a TV monitor, and subtended a visual angle of approximately $1.5 \times 0.5 \mathrm{deg}$. Exposure duration was $300 \mathrm{~ms}$, and the interstimulus interval was $3 \mathrm{~s}$. A fixation dot was continuously present on the monitor except for the period $150 \mathrm{~ms}$ before stimulus onset until $924 \mathrm{~ms}$ thereafter. An experimental run consisted of 200 trials, with a short rest halfway through. Data from one run on this task were collected from the patient in January 1989 , and each of the controls also carried out a single run of this task.

$E R P$ recording ERPs were recorded from three midline scalp sites, $\mathrm{Fz}, \mathrm{Cz}$, and $\mathrm{Pz}$, and from lateral electrodes over the left and right frontal (midway between F3 and F7, and F4 and F8), temporal (T3 and T4) and the inferior parietal (mid-way between P3 and T5, and P4 and T6) regions. All scalp recordings were made with respect to a balanced sternovertebral reference. ${ }^{17}$ Vertical and horizontal EOG were recorded from bipolar electrode pairs placed above and below the right eye (vertical), and on the outer canthus of each eye (horizontal). EEG and EOG were recorded with bandwidths of $0.03-30 \mathrm{~Hz}$ ( $3 \mathrm{~dB}$ points) and digitised on-line at a rate of $4 \mathrm{~ms} /$ point for $1024 \mathrm{~ms}$, starting $100 \mathrm{~ms}$ before stimulus onset.

Target and non-target ERPs were averaged off-line. In the visual task, any trial associated with a response error or EOG artefact was rejected, as were trials on which amplifierblocking occurred. The patient's data from one run of the auditory oddball task contained an excessive number of trials containing blink artefacts. These artefacts were removed statistically with a procedure similar to that described by Semlitsch, et $a ;^{18}$ the same procedure was applied to her data from the other run of the auditory task, and to each of the ERPs of the controls. The application of the EOG correction procedure is very unlikely to have introduced significant error into the comparison between the waveforms of the patient and the controls. The conventionally-
Figure 2 Upper-ERPs from the patient evoked by target and non-target stimuli in two runs of the auditory oddball task. Lower-Grand-average of the controls' waveforms in the same task.
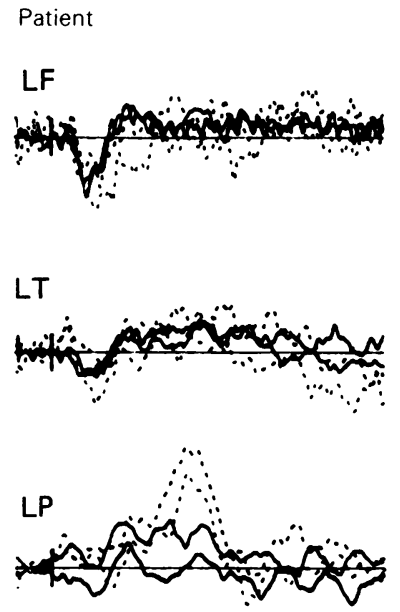

Controls
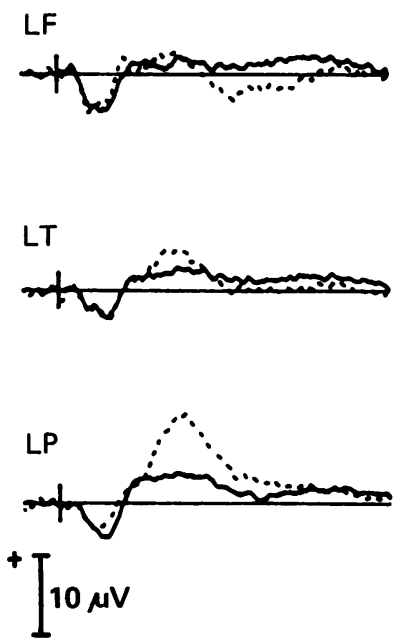
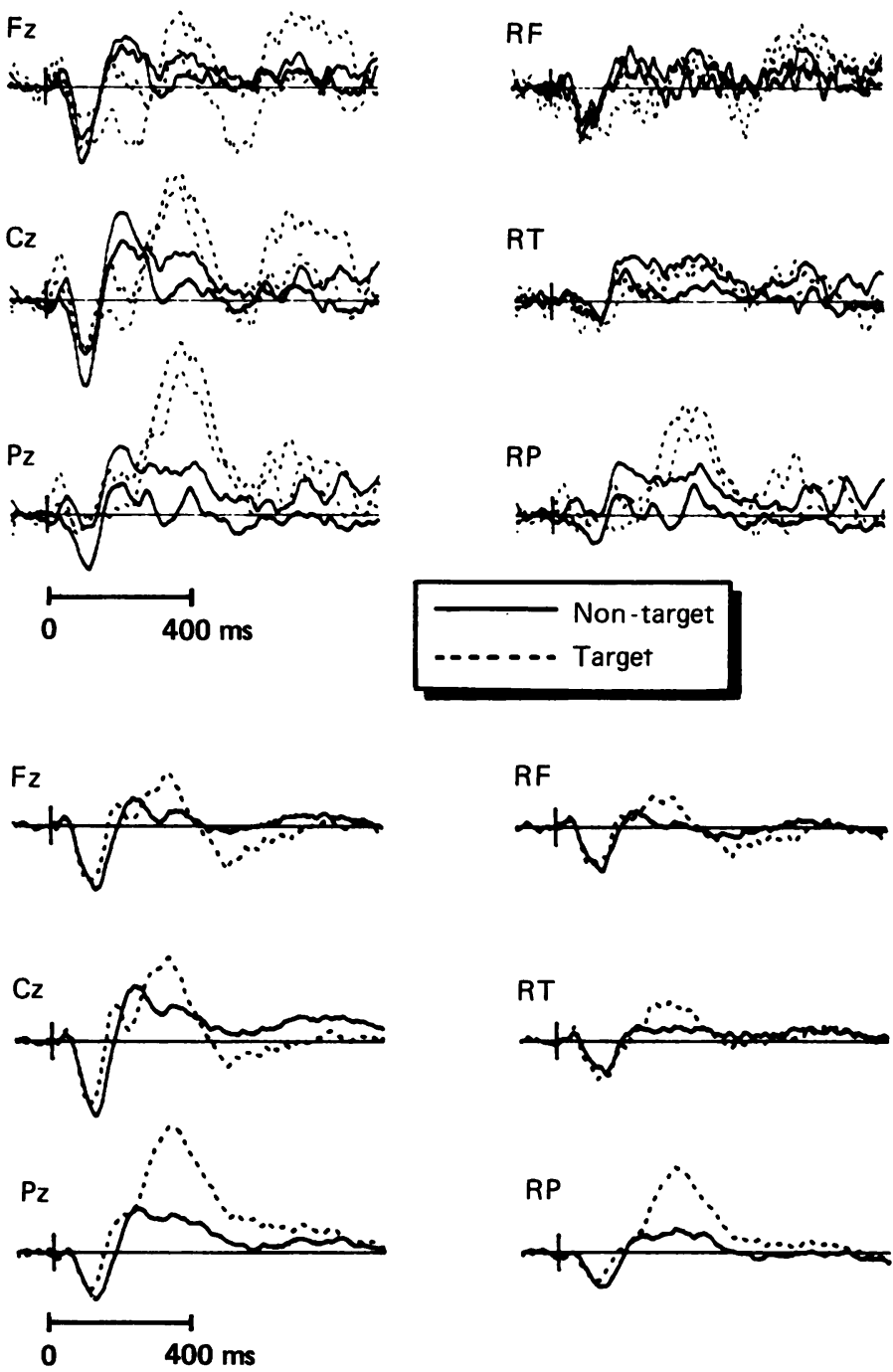
Table 2 Peak latency (ms) and amplitude (microvolts) of the P300 evoked by targets from the parietal electrodes of the patient and the controls

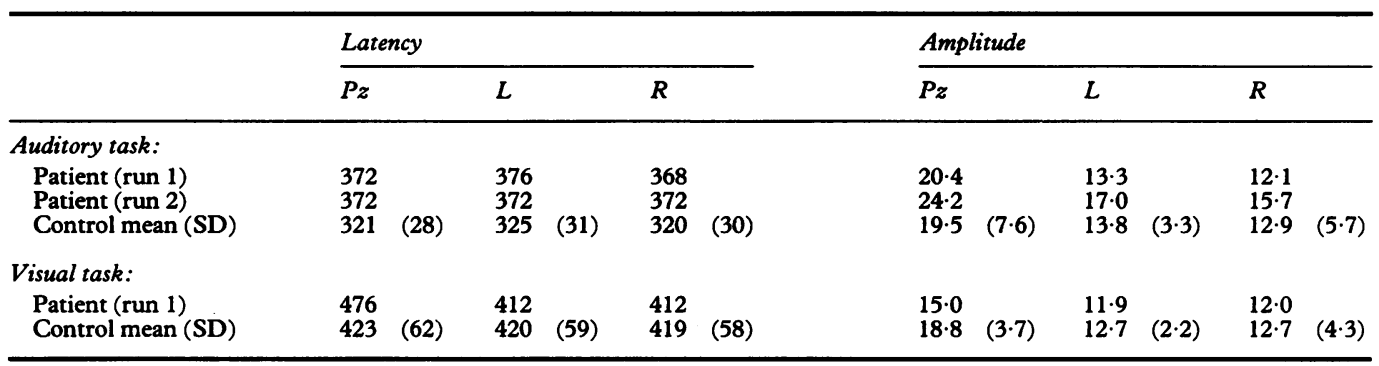

averaged auditory ERPs of the controls were almost identical to those obtained after application of the procedure, and the same held true for the patient's data from her run on this task which did not require EOG correction.

\section{Results}

Auditory task The patient's reaction time (RT) to targets was 399 ms (across-trials SD = $100 \mathrm{~ms}$ ) on run 1 and $383 \mathrm{~ms}(\mathrm{SD}=86 \mathrm{~ms})$ on run 2. The mean $R T$ of the controls was $483 \mathrm{~ms}$ (across-subjects SD = $148 \mathrm{~ms}$ ). She made no errors of omission on either run, and made only one error of commission, on run 1. The greatest number of errors made by any control subject was 7 .

The patient's target and non-target ERPs are illustrated in fig 2. Compared with the nontarget waveforms, the target ERPs from the midline sites contain a prominent frontocentral "N2" component, peaking at approximately $220 \mathrm{~ms}$, followed by a large parietal P300, peaking at approximately $370 \mathrm{~ms}$. The P300 is also prominent at the lateral parietal electrodes, at which it appears to be almost symmetrical in both amplitude and latency. Figure 1 also illustrates the grandaverage of the controls' ERPs; these are qualitatively very similar to those of the patient.

Clearly identifiable target $P 300$ s were present in every subjects' parietal recordings, allowing the determination of the peak latency and amplitude of this component from each subject. These data are summarised in table 2 . The latency of $\mathrm{P} 300$ at $\mathrm{Pz}$ is $32 \mathrm{~ms}$ longer in the patient than that in the nearest control. However, as in the controls, the latencies of the P300s from her two lateral parietal electrodes differ at most by only a few milliseconds. In the case of the peak amplitude of $\mathrm{P} 300$ (measured with respect to the mean of the $100 \mathrm{~ms}$ prestimulus baseline), the patient's values are clearly within the normal range and show, as with the controls, a slight tendency to be larger over the left than the right hemisphere.

To measure amplitude in the P300 latency range of target and non-target ERPs from all electrode sites, the mean amplitude of the $24 \mathrm{~ms}$ region straddling the peak latency of $\mathrm{P} 300$ at $\mathrm{Pz}$ was computed. These data are shown in table 3. As with the peak measures of the target P300, the patient's data fall within the normal range. This is true also for the differences in amplitude between target and non-target ERPs, a measure of the "responsiveness" of P300 to the target/non-target manipulation.

Visual task The patient's RT to targets was $507 \mathrm{~ms}$ (across-trials SD = $94 \mathrm{~ms}$ ). She made one error of omission, and none of commission. The mean RT of the controls was $624 \mathrm{~ms}$ (across subjects $\mathrm{SD}=127 \mathrm{~ms}$ ). All but one control (who made one error of omission) were error-free on this task.

The visual ERPs for the patient are shown in fig 3. Her target waveforms exhibit a substantial

Table 3 Mean amplitude (microvolts) of the 24 ms latency window centred on the peak of P300 at Pz for the patient and controls' target and non-target waveforms

\begin{tabular}{|c|c|c|c|c|c|c|c|c|c|}
\hline & $F z$ & $C z$ & $P z$ & $L F$ & $L T$ & $L P$ & $R F$ & $R T$ & $R P$ \\
\hline \multicolumn{10}{|l|}{ Auditory task: } \\
\hline \multicolumn{10}{|l|}{ Patient: } \\
\hline $\begin{array}{l}\text { Target } \\
\text { Non-target }\end{array}$ & $\begin{array}{l}4 \cdot 5 \\
4 \cdot 2\end{array}$ & $\begin{array}{r}15 \cdot 5 \\
6 \cdot 7\end{array}$ & $\begin{array}{r}19.8 \\
5.9\end{array}$ & $\begin{array}{r}-0 \cdot 1 \\
2 \cdot 4\end{array}$ & $\begin{array}{l}1.2 \\
1.4\end{array}$ & $\begin{array}{r}12 \cdot 2 \\
3 \cdot 4\end{array}$ & $\begin{array}{l}3.0 \\
3.4\end{array}$ & $\begin{array}{l}5 \cdot 7 \\
5 \cdot 7\end{array}$ & $\begin{array}{r}11 \cdot 7 \\
5 \cdot 4\end{array}$ \\
\hline \multicolumn{10}{|l|}{ Run 2: } \\
\hline $\begin{array}{l}\text { Target } \\
\text { Non-target }\end{array}$ & $\begin{array}{r}10.0 \\
1.2\end{array}$ & $\begin{array}{r}17.6 \\
1.9\end{array}$ & $\begin{array}{r}23.5 \\
1.0\end{array}$ & $\begin{array}{l}3 \cdot 3 \\
1 \cdot 1\end{array}$ & $\begin{array}{l}5 \cdot 5 \\
3 \cdot 2\end{array}$ & $\begin{array}{r}16 \cdot 2 \\
0 \cdot 1\end{array}$ & $\begin{array}{l}4 \cdot 2 \\
1 \cdot 0\end{array}$ & $\begin{array}{l}4 \cdot 7 \\
1 \cdot 3\end{array}$ & $\begin{array}{r}15 \cdot 1 \\
1 \cdot 3\end{array}$ \\
\hline \multicolumn{10}{|l|}{ Controls: } \\
\hline $\begin{array}{l}\text { Target } \\
\text { SD } \\
\text { Non-target } \\
\text { SD }\end{array}$ & $\begin{array}{l}7.2 \\
4 \cdot 8 \\
1.9 \\
3 \cdot 4\end{array}$ & $\begin{array}{r}12 \cdot 4 \\
7 \cdot 4 \\
4 \cdot 8 \\
4 \cdot 3\end{array}$ & $\begin{array}{r}19 \cdot 1 \\
7 \cdot 6 \\
5 \cdot 2 \\
2 \cdot 3\end{array}$ & $\begin{array}{l}3 \cdot 9 \\
1 \cdot 8 \\
2 \cdot 1 \\
2 \cdot 1\end{array}$ & $\begin{array}{l}6 \cdot 6 \\
2 \cdot 3 \\
2 \cdot 9 \\
1 \cdot 6\end{array}$ & $\begin{array}{r}13 \cdot 2 \\
3 \cdot 4 \\
4 \cdot 1 \\
1 \cdot 5\end{array}$ & $\begin{array}{l}4 \cdot 6 \\
4 \cdot 2 \\
0 \cdot 6 \\
2 \cdot 9\end{array}$ & $\begin{array}{l}6 \cdot 3 \\
4 \cdot 8 \\
2 \cdot 0 \\
2 \cdot 2\end{array}$ & $\begin{array}{r}12 \cdot 6 \\
5 \cdot 8 \\
3 \cdot 0 \\
2 \cdot 7\end{array}$ \\
\hline \multicolumn{10}{|l|}{ Visual task: } \\
\hline $\begin{array}{l}\text { Patient: } \\
\text { Target } \\
\text { Non-target }\end{array}$ & $\begin{array}{r}-6 \cdot 9 \\
3 \cdot 3\end{array}$ & $\begin{array}{l}3.8 \\
3.6\end{array}$ & $\begin{array}{r}14.5 \\
3.9\end{array}$ & $\begin{array}{r}-7 \cdot 8 \\
3 \cdot 1\end{array}$ & $\begin{array}{l}1 \cdot 3 \\
2 \cdot 6\end{array}$ & $\begin{array}{r}11 \cdot 0 \\
2 \cdot 6\end{array}$ & $\begin{array}{r}-3.9 \\
5.9\end{array}$ & $\begin{array}{l}4 \cdot 3 \\
4 \cdot 3\end{array}$ & $\begin{array}{l}9 \cdot 7 \\
0.9\end{array}$ \\
\hline Controls: & & & & & & & & & \\
\hline $\begin{array}{l}\text { Target } \\
\text { SD } \\
\text { Non-target } \\
\text { SD }\end{array}$ & $\begin{array}{l}9.5 \\
0.9 \\
7 \cdot 8 \\
2.9\end{array}$ & $\begin{array}{r}12.5 \\
2.8 \\
11.2 \\
4.0\end{array}$ & $\begin{array}{r}18.3 \\
3.6 \\
10.6 \\
2.9\end{array}$ & $\begin{array}{l}7 \cdot 1 \\
1 \cdot 2 \\
5 \cdot 6 \\
2 \cdot 2\end{array}$ & $\begin{array}{l}5 \cdot 9 \\
1 \cdot 2 \\
4 \cdot 2 \\
0 \cdot 7\end{array}$ & $\begin{array}{r}12 \cdot 1 \\
2 \cdot 1 \\
6 \cdot 2 \\
2 \cdot 4\end{array}$ & $\begin{array}{l}7 \cdot 3 \\
2 \cdot 7 \\
5 \cdot 0 \\
2 \cdot 1\end{array}$ & $\begin{array}{l}6.6 \\
2.5 \\
4 \cdot 5 \\
1 \cdot 0\end{array}$ & $\begin{array}{r}12 \cdot 2 \\
4 \cdot 3 \\
6 \cdot 8 \\
2 \cdot 1\end{array}$ \\
\hline
\end{tabular}


Figure 3 Upper-ERPs from the patient evoked by target and non-target stimuli in the visual oddball task. LowerGrand-average of the controls' waveforms in the same task.
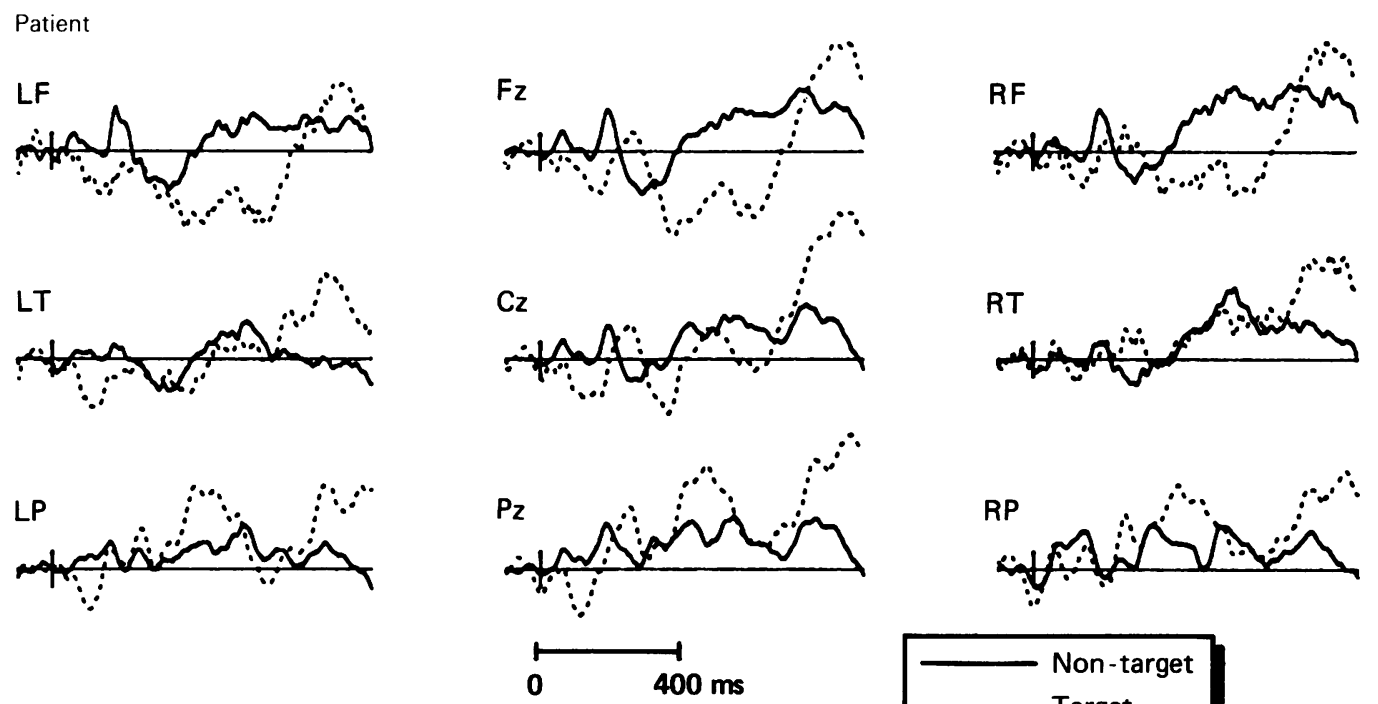

Controls
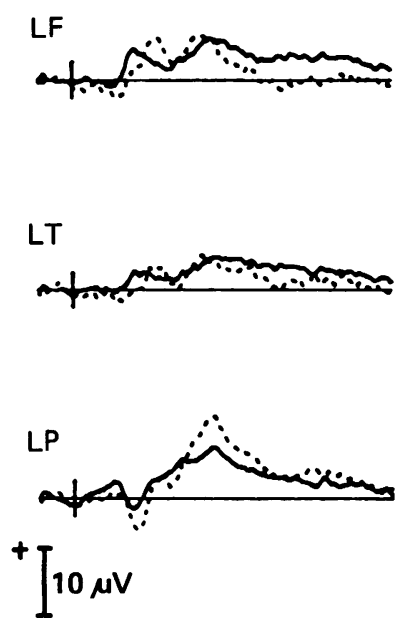
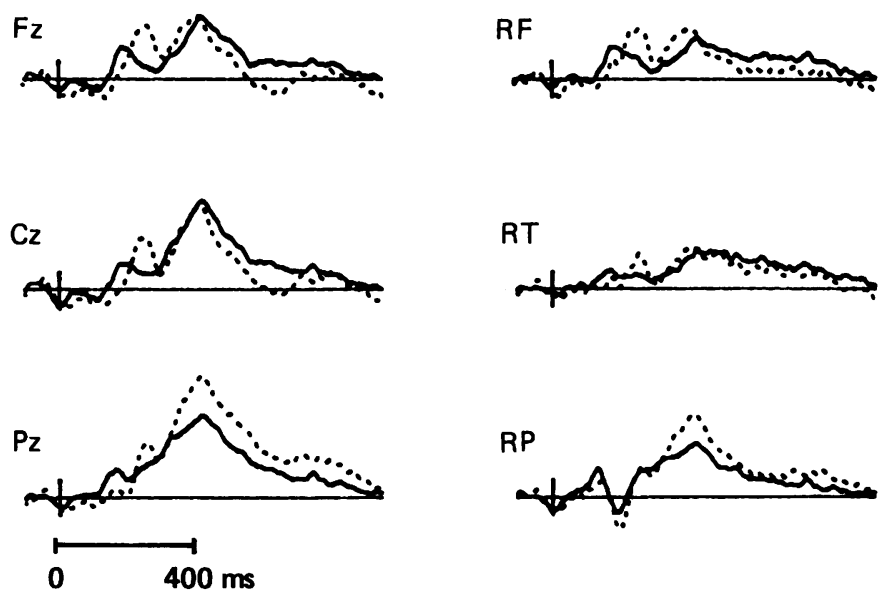

negative-going slow wave, which is terminated by a late, fronto-centrally distributed positive wave (her averaged EOG waveforms indicate these features of her ERPs are not of ocular origin). A target-related P300 is clearly evident from the parietal electrodes and, as with the auditory P300, shows no asymmetry between left and right parietal regions. The visual data for the patient and the controls were quantified in the same way as those from the auditory task, and are shown in tables 2 and 3. The data in table 3 suggest that the target-evoked negativity that is evident from the patient's frontal electrodes is abnormally large. Despite the size of this frontal negativity, the peak amplitude of her parietal P300, and the target/ non-target differences from the parietal electrodes in the $\mathrm{P} 300$ latency region, are well within the normal range.

\section{Discussion}

These data suggest that normal auditory and visual parietal P300 components can be generated despite extensive pathology of the left MTL. One problem in the interpretation of these findings lies in the nature of this pathology; tumours can cause signal change in CT and MRI without concomitant neuronal dysfunction, ${ }^{19}$ leading to uncertainty about the extent of neuronal damage.

In the case we describe, the disturbance of cognitive function attributable to pathology was both severe and of a form consistent with major dysfunction of the left MTL. The patient's verbal memory deficit was comparable to that of a group of patients with infarcts in the region of the left posterior parahippocampal gyrus and collateral isthmus, ${ }^{20}$ a lesion presumed by Von Cramon et al $^{20}$ to disconnect the entire hippocampal formation from association cortex. The severity of the verbal memory impairment therefore makes it very unlikely that her left MTL is functionally competent.

Assuming that the patient's left MTL structures are grossly dysfunctional, then our findings are difficult to reconcile with the idea that the posterior hippocampal formation makes a significant contribution to the scalp P300; the patient's P300s were neither asymmetric nor of abnormally low amplitude. Thus these findings complement those of studies of the effects of unilateral temporal lobectomy (see introduction), and suggest that normal P300 following this procedure reflects neither the presence of a 
unilateral skull defect, nor the failure to remove a critical region of the MTL. The present data are also consistent with the finding that bilateral amygdalohippocampectomy has no effect on a monkey analogue of P300. ${ }^{21}$

Although extensive, the patient's pathology spared the lateral cortex, and lateral cortical damage following anterior temporal lobectomy is confined to the anterior regions. It therefore seems that unilateral damage neither to medial temporal regions, nor to anterior lateral temporal cortex, is sufficient to disrupt the generation of P300. By contrast, the auditory oddballevoked P300 is reported to be considerably attenuated after unilateral cortical damage in the vicinity of the temporo-parietal junction. ${ }^{22}$ The focus of interest for future lesion studies of P300 seems likely to move from medial temporal to lateral/posterior cortical regions.

1 Verleger R. Event-related potentials and cognition: A critique of the context updating hypothesis and an alternative explanation of P3. Behav Brain Sci 1989;11:343-56.

2 Polich J. P300 in the evaluation of aging and dementia. In Proceedings of the Ninth International Conference on Event-Related Potentials of the Brian. Electroeneceph Clin Neurophysiol (suppl), (in press)

3 Duncan-Johnson CC, Donchin E. On quantifying surprise: The variation of event-related potentials with subjective probability. Psychophysiol 1977;14:456-67.

4 Halgren E, Squires NK, Wilson CL, Rohrbaugh JW, Babb $\mathrm{TL}, \mathrm{Crandall} \mathrm{PH}$. Endogenous potentials generated in the human hippocampal formation and amygdala by infrequent events. Science 1980;210:803-5.

5 McCarthy G, Wood CC, Williamson PD, Spencer DD. Task-dependent field potentials in human hippocampal formation. J Neurosc 1989;9:4253-8.

6 Stapleton JM, Halgren E. Endogenous potentials evoked in simple cognitive tasks: depth components and task corsimple cognitive tasks: depth components and task cor-

7 Wood CC, McCarthy G, Squires NK, Vaughan HG, Woods $\mathrm{DL}, \mathrm{McC}$ allum WC. Anatomical and physiological substrates of event-related potentials. In: R Karrer, J Cohen, $\mathrm{P}$ Tueting, eds. Brain and information: Event-related potentials. New York: New York Academy of Science, 1984:681-721.

8 Meador KJ, Loring DW, King DW, et al. Limbic evoked potentials predict site of epileptic focus. Neurol 1987; 37:494-7.

9 Puce A, Kalnins RM, Berkovic SF, Donnan GA, Bladin PF Limbic P3 potentials, seizure localisation and surgical pathology in temporal lobe epilepsy. Ann Neurol 1989;26:377-85.

10 Wood CC, McCarthy G, Kim GH, Spencer DD, Williamson PD. Abnormalities in temporal lobe ERPs predict hippocampal cell loss in temporal lobe epilepsy. Soc Neurosc Abs 1988;14:5.

11 Johnson R. Scalp-recorded P300 activity in patients following unilateral temporal lobectomy. Brain 1988;111: ing unilater $1517-29$.

12 Johnson R, Fedio P. P300 activity following unilateral temporal lobectomy: a preliminary report. In: McCallum WC, Zappoli R, Denoth F, eds, Cerebral psychophysiology: studies in event-related potentials. Amsterdam Elsevier, 1986:552-4.

13 Stapleton JM, Halgren E, Moreno KA. Endogenous potentials after anterior temporal lobectomy. Neuropsychologia 1987;25:549-57.

14 Wood CC, McCarthy G, Allison T, Goff WR, Williamson PD, Spencer DD. Endogenous event-related potentials following temporal lobe excisions in humans. Soc Neurosc Abs 1982;8:976.

15 Knight RT. Neural mechanisms of event-related potentials: evidence from human lesion studies. In: Rohrbaugh JW, evidence from human lesion studies. In: Rohrbaugh JW, potentials: issues and interdisciplinary vantages. New York: potentials: issues and interdi

16 Awad IA, Katz A, Hahn JE, Kong AK, Ahl J, Luders H. Extent of resection in temporal lobectomy for epilepsy. I. Interobserver analysis and correlation with seizure outcome. Epilepsia 1989;30:756-62.

17 Stephenson WA, Gibbs FA. A balanced non-cephalic reference electrode. Electroenceph Clin Neurophysiol 1951 3:237-40.

18 Semlitsch HV, Anderer P, Schuster P, Presslich O. A solution for reliable and valid reduction of ocular artifacts, applied to the P300 ERP. Psychophysiol 1986;23:695-703.

19 Damasio H, Damasio AR. Lesion analysis in neuropsychology. New York: Oxford University Press, 1989.

20 Von Cramon HY, Hebel N, Schuri U. Verbal memory and learning in unilateral posterior cerebral infarction. Brain 1988;111:1061-77.

21 Paller KA, Zola-Morgan S, Squire LR, Hillyard SA. P3-like brain waves in normal monkeys and monkeys with medial brain waves in normal monkeys and monkeys with

22 Knight RT, Scabini D, Woods DL, Clayworth CC. Contributions of temporo-parietal junction to the human auditory P3. Brain Res 1989;13:109-16.

23 Lezak MD. Neuropsychological assessment. New York Oxford University Press, 1976 